\title{
Radiofrequency radiation from nearby mobile phone base stations-a case comparison of one low and one high exposure apartment
}

\author{
TARMO KOPPEL $^{1}$, MIKKO AHONEN ${ }^{2}$, MICHAEL CARLBERG $^{3}$, \\ LENA K. HEDENDAHL ${ }^{3}$ and LENNART HARDELL ${ }^{3}$ \\ ${ }^{1}$ Department of Labour Environment and Safety, Tallinn University of Technology, Tallinn 19086; \\ ${ }^{2}$ Institute of Environmental Health and Safety, Tallinn 11615, Estonia; \\ ${ }^{3}$ The Environment and Cancer Research Foundation, SE-702 17 Örebro, Sweden
}

Received May 10, 2019; Accepted August 5, 2019

DOI: $10.3892 / \mathrm{ol} .2019 .10899$

\begin{abstract}
Radiofrequency (RF) radiation in the frequency range of $30-300 \mathrm{GHz}$ has, since 2011 , been classified as a 'possible' human carcinogen by Group 2B, International Agency for Research on Cancer (IARC) at WHO. This was based on a number of human epidemiology studies on increased risk for glioma and acoustic neuroma. Based on further human epidemiology studies and animal studies, the evidence on RF radiation carcinogenesis has increased since 2011 . In previous measurement studies, it has been indicated that high environmental RF radiation levels are present in certain areas of Stockholm Sweden, including in one apartment. Field spatial distribution measurements were performed in the previously measured apartment in Stockholm, which exhibited high $\mathrm{RF}$ radiation from nearby base stations. Based on the RF broadband analyzer spot measurements, the maximum indoor E-field topped at $3 \mathrm{~V} \mathrm{~m}^{-1}$ in the bedroom at the 7 th floor. The maximum outdoor exposure level of $6 \mathrm{~V} \mathrm{~m}^{-1}$ was encountered at the 8th floor balcony, located at the same elevation and only $6.16 \mathrm{~m}$ away from the base station antennas. For comparison, a measurement was made in a low exposure apartment in Stockholm. Here, the maximum indoor field $0.52 \mathrm{~V} \mathrm{~m}^{-1}$ was measured at the corner window, with direct line of sight to the neighboring house with mobile phone base station antennas. The maximum outdoor field of $0.75 \mathrm{~V} \mathrm{~m}^{-1}$ was measured at the balcony facing the same next-door building with mobile phone base station antennas. The minimum field of $0.10 \mathrm{~V} \mathrm{~m}^{-1}$ was registered on the apartment area closest to the center of the building, demonstrating the shielding effects of the indoor
\end{abstract}

Correspondence to: Professor Lennart Hardell, The Environment and Cancer Research Foundation, Studievägen 35, SE-702 17 Örebro, Sweden

E-mail: lennart.hardell@environmentandcancer.com

Key words: radiofrequency radiation, microwaves, mobile phone, base stations, exposure, health, building walls. Good mobile phone reception was achieved in both apartments. Therefore, installation of base stations to risky places cannot be justified using the good reception requirement argument.

\section{Introduction}

Public exposure to radiofrequency (RF) electromagnetic fields (EMF) in today's cities may be caused by a number of sources, including mobile phone base stations, TV and radio towers, wireless local area networks (WLAN), emergency services radio network, RF-identification systems, microwave ovens, anti-theft gates etc. Additionally, individual's exposure may be significantly elevated by personal usage of mobile and cordless phones, 2-way radios, WLAN, Bluetooth and other wireless devices. In this study we have focused on the exposure from mobile phone base station antennas. Exposure in two apartments positioned close to mobile phone base station antennas is measured in detail.

Developments in telecommunications technologies have led to widespread use of mobile devices connected to the network in constantly increasing loads. This has resulted also in the public's exposure to RF EMFs. Temporal trends in RF EMF exposure in everyday environments were investigated across European cities of Basel, Ghent and Brussels in 2011-2012 (1). Within a year total RF exposure levels in all investigated outdoor locations combined raised $57.1 \%$. The increase in exposure was most notably observed in outdoor locations due to mobile phone base stations (1).

In many European countries on-site RF exposure measurements have been conducted since the 1990's. Most studies have focused on the mobile communications' frequency bands. A comparative analysis concluded that due to the developments in telecommunications technology, the RF exposure is continuously increasing and is estimated $>65 \%$ of the total exposure (2). Based on the personal exposure measurements in the EU, the mean RF is generally from 0.10 to $0.26 \mathrm{~V} \mathrm{~m}^{-1}$; however most of these studies are based on outdoor measurements.

RF field exposure literature in Europe was reviewed, comparing indoor levels to outdoor levels (3). The mean RF 
exposure from spot measurements in homes was determined to be $0.29 \mathrm{~V} \mathrm{~m}^{-1}$ and for outdoor $0.54 \mathrm{~V} \mathrm{~m}^{-1}$. In outdoor studies the exposure levels rarely exceeded $1.0 \mathrm{~V} \mathrm{~m}^{-1}$, whereas the highest exposure contributor was the downlink i.e., radiation from mobile phone base station antenna. A finding of the systematic review was that there was no distinct difference in exposure levels between European countries. However, studies done by different researchers across the Europe have used different procedures limiting the comparability between studies (3).

RF levels are exponentially higher when located closer to the mobile phone base station antenna. Therefore, proper safety measures must be applied when protecting public from the excess RF radiation. One of the main safety principles is creating sufficient distance between the public and the RF sources. This requirement may not be met in certain housing conditions. Mobile phone base stations installed on rooftops may become very close to people in nearby apartments.

RF field exposure from a mobile phone base station antenna, located at the rooftop showed that allowable maximum safety levels were exceeded when being closer than $30 \mathrm{~m}$ to the base station antenna (4). With the increasing distance, the RF power density is increasingly affected by the landscape topography, buildings, and trees that induce reflection and absorption. Also, RF power density depends on the numbers of channels in use by the base station antenna, the number of time intervals used and other mobile communication specific factors. The base station's maximum RF level varies across the day, which is an indicator of the mobile communications' service load. Also, RF power density distribution is greatly determined by the antenna's directional pattern. Values were measured highest in the balconies within the main radiation lobe of the antenna (4).

We have previously reported results from our measurements of RF radiation levels at certain places in Stockholm, Sweden such as at the Central Railway station (5), the Old Town (6), and in the City (7). High radiation was measured at a square, Järntorget, in the Old Town as further displayed in a recent publication displaying RF E-field distribution (8). Most of the radiation was downlink.

Of special concern is our results of measurements in a Stockholm apartment for everyday living purposes (9). Two groups of base stations are located close to the apartment. The total mean RF radiation level was $3,811 \mu \mathrm{W} / \mathrm{m}^{2}$ (range 15.2-112,318 $\mu \mathrm{W} / \mathrm{m}^{2}$ ) for the measurement of the whole apartment, including balconies. Particularly high levels were measured on three balconies and in 3 of 4 bedrooms. High mean exposure levels in the bedrooms of growing children (one at $2,531 \mu \mathrm{W} / \mathrm{m}^{2}$ and the other at $1,471 \mu \mathrm{W} / \mathrm{m}^{2}$ ) with maximum peaks at 11,803 and $13,739 \mu \mathrm{W} / \mathrm{m}^{2}$, respectively, may have deleterious effects on their physical and mental health $(9,10)$.

The aim of this study was to further investigate radiation levels in the high exposure apartment (9) and to compare it with a low exposure apartment showing RF E-field distribution. This was a measurement study with no involvement of test persons. Thus, no ethical permission was needed.

\section{Materials and methods}

In the present study RF field levels were investigated in two apartments near mobile phone base station antennas. One of the apartments represented a high exposure living area, while the other was of low exposure area. Both of the apartments were near to mobile phone base stations but located at different city districts in Stockholm, Sweden. The locations of the base stations close to the apartment with high RF radiation exposure are shown in Figs. 1 and 2, whereas the base stations relating to the low exposure apartment are shown in Fig. 3.

The high exposure apartment's outdoor areas were positioned close to the mobile phone base station antennas, being as close as $6 \mathrm{~m}$. The low exposure apartment's balcony was about $40 \mathrm{~m}$ away from the base station antennas, since these were installed on the neighboring building and significantly higher on the roof.

Field spatial distribution measurements were conducted in the investigated apartments. The following analyses bring forth the low and high exposure determinant factors. RF electric field was measured at each room of the apartments. Depending on the room size, the room was divided into two to ten quadrants (smaller imaginary squares). At each quadrant a spot measurement was conducted. At each spot the field was measured with slow circular movements to cover the area of about $1 \mathrm{~m}^{2}$ at heights of 0.7-2 $\mathrm{m}$. At each spot, the average and maximum electric field in Volts per meter $\left(\mathrm{V} \mathrm{m}^{-1}\right)$ was recorded representing the measurement period of about $1 \mathrm{~min}$.

The measurements were conducted on a working day during business hours (afternoon) in January 2019.

Field perturbation by the measurer was minimized by distancing the meter from the body-the meter was held at arm's length, with the extending probe outward. The measurements area was therefore at about $0.8-0.9 \mathrm{~m}$ from the investigator.

Spot distance to mobile phone base station antenna was measured by targeting the closest antenna element. Distance was measured by laser distance meter STABILA LE50, which provides precise distance measurements up to $100 \mathrm{~m}$ with the resolution of $0.001 \mathrm{~m}$ at the accuracy $\pm 1.5 \mathrm{~mm} / \mathrm{m}$.

The measurements were conducted with a RF broadband analyzer, Narda NBM-520, with a E-field probe E0391 (Narda-Safety-Test-Solutions GmbH, Pfullingen, Germany). The Narda NBM-series meter is capable of time and spatial averaging and determining the maximum level during the period monitored. Narda EF0391 probe is intended by the manufacturer for base station measurements and has a frequency range from $100 \mathrm{kHz}$ to $3 \mathrm{GHz}$.

The broadband meter Narda EF0391 covers a large range of RF transmissions, including different telecommunications protocols: frequency modulation (FM) radio broadcasting; television (TV) broadcasting; TETRA emergency services (police, rescue, etc.); global system for mobile communications (GSM) second generation mobile communications; universal mobile telecommunications systems (UMTS) third generation mobile communications, 3G; long-term evolution (LTE) fourth generation mobile communications standard, 4G; digital European cordless telecommunications (DECT) cordless telephone systems standard; Wi-Fi wireless local area network protocol, $2.45 \mathrm{GHz}$; worldwide interoperability for microwave access (WIMAX) wireless communication standard for high speed voice, data and internet.

Mobile communications' service coverage reception level was confirmed using an Android mobile phone, showing service coverage in decibel milliwatts $(\mathrm{dBm})$. 


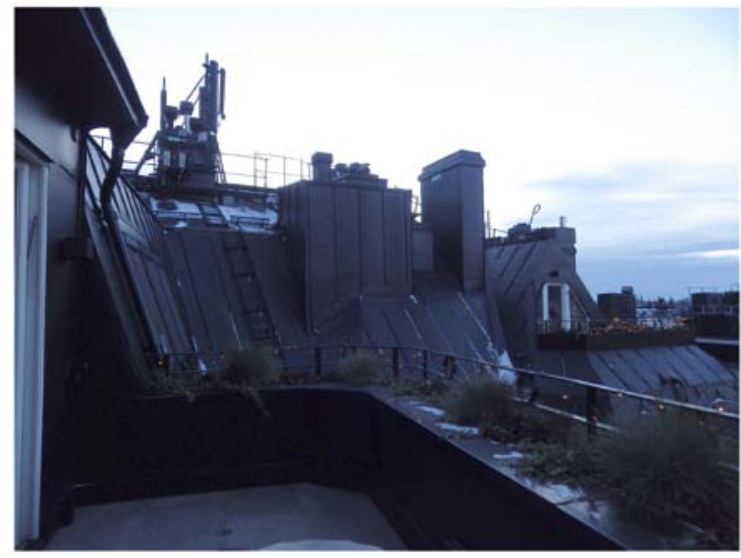

Figure 1. A view from the high exposure apartment's balcony, this was one of the highest exposure areas in the apartment's main floor with the RF field topping at $5.1 \mathrm{~V} \mathrm{~m}^{-1}$, base station antenna as $11.87 \mathrm{~m}$ away from the fence. $\mathrm{RF}$, radiofrequency.

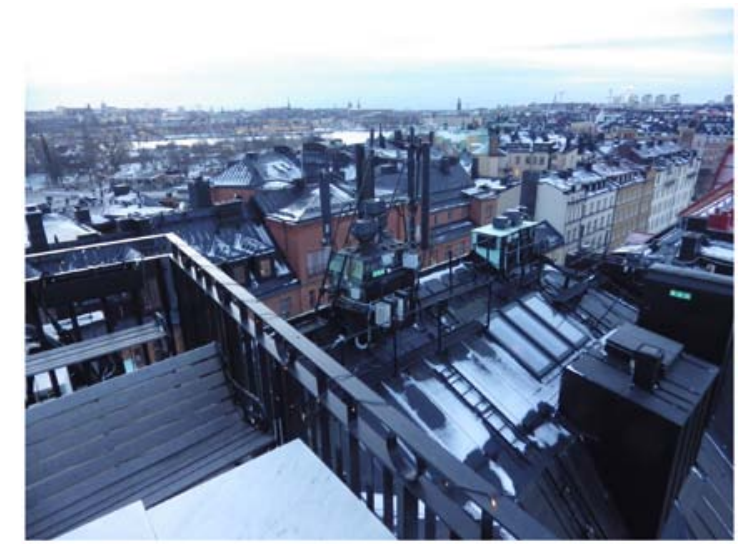

Figure 2. A view from the high exposure apartment's balcony, a set of mobile phone base station antennas are $6 \mathrm{~m}$ away from the fence; this was the highest radiation area, with the $\mathrm{RF}$ exposure topping at $6 \mathrm{~V} \mathrm{~m}^{-1}$, even though the antennas sector was positioned away from the balcony. RF, radiofrequency.

In the present study, measurement data are presented both in tables and visual views. Spatial distribution of the RF levels is presented in a heat map view. Heat map is possible only by a volume of spatially scattered spot measurements. Heat map is also seen by some other authors as a way to communicate the measurements data in a comprehensible way to the public (11).

The measurement data, specifically average spot measurement values, were entered to the contour map software 3DFIELD ver. 4.5.2.0 (by Vladimir Galouchko) and spatial field distribution maps were drawn. Field distribution maps were based on the spot measurements using 1 min time averaging.

Conversion from $\mathrm{V} \mathrm{m}^{-1}$, to $\mathrm{W} / \mathrm{m}^{2}$, see also Table I. In most of our earlier studies we have used the EME Spy 200 from Satimo and preferred to show our results in power flux density in $\mathrm{W} / \mathrm{m}^{2}$ and $\mu \mathrm{W} / \mathrm{m}^{2}$ for $\mathrm{RF}$ radiation. In the current measurements the broadband analyzer Narda NBM-520 measures in V $\mathrm{m}^{-1}$ and the contour map software 3DFIELD is also constructed for measurements in $\mathrm{V} \mathrm{m}^{-1}$.

To convert from electric field strength, $\mathrm{E}$, in $\mathrm{V} \mathrm{m}^{-1}$ to power flux density in $\mathrm{W} / \mathrm{m}^{2}, \mathrm{~S}$, use the formula: $\mathrm{S}=0.002654 \times \mathrm{E}^{2}$

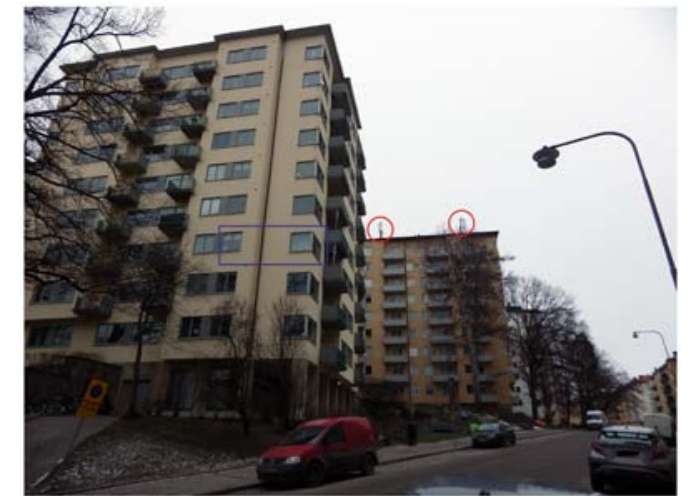

Figure 3. View to the low exposure apartment (rectangle). Mobile phone base station antennas are visible on the neighboring building (circled); the highest RF exposure level was on the balcony, which had the line of sight to both of the antennas. However due to the elevation difference, the balcony had highest electric field only $0.75 \mathrm{~V} \mathrm{~m}^{-1}$; based on spot measurements maximum readings over 1-min period; base station antennas' sector include the investigated building. Rectangle, low exposure apartment; circle, neighboring building. RF, radiofrequency.

Statistical methods. The data was analyzed using the spreadsheet software Microsoft Excel 2016, calculating mean, median, minimum and maximum for the measured areas. Mean $(\overline{\mathrm{x}})$, median, and minimum values were based on the time averaging function of spot measurements; maximum value was based on the maximum reading registered during the spot measurement. Differences in field level across different areas was compared in a table and illustrated in a box plot and the factors determining the attenuation/elevation of the field pointed out.

\section{Results}

The field spatial distribution measurements conducted at the apartments in Stockholm show great variation in the RF field levels.

High exposure apartment. As illustrated in Figs. 4-6, the propagation of the field from the nearby mobile phone base stations' several antennas in the high exposure apartment. Based on the RF broadband analyzer spot measurements, the maximum indoor E-field topped at $3 \mathrm{~V} \mathrm{~m}^{-1}$ at the bedroom on the 7th floor. The maximum outdoor exposure level of $6 \mathrm{~V} \mathrm{~m}^{-1}$ was encountered on the 8th floor balcony, located at the same elevation and only $6.16 \mathrm{~m}$ away from the base station antennas. Outdoor areas i.e. balconies have notably higher exposure, indicated by the darker color.

High exposure levels were encountered also on the 6th floor balcony with a direct line of sight to the mobile phone base station antenna at $11.87 \mathrm{~m}$ distance. Since the base station antenna was not aimed at the aforementioned area, hence even higher exposure conditions are avoided. The lowest exposure area is in the middle of the apartment $\left(0.30 \mathrm{~V} \mathrm{~m}^{-1}\right)$, which is still twice as high as the mean exposure level of the low exposure apartment $\left(0.16 \mathrm{~V} \mathrm{~m}^{-1}\right)$.

Low exposure apartment. RF field in the low exposure apartment is illustrated in Fig. 7. The field distribution in low 
Table I. Conversion table from E, Electric field strength in $\mathrm{V} \mathrm{m}^{-1}$ to S, power flux density in $\mu \mathrm{W} / \mathrm{m}^{2}$.

\begin{tabular}{lc}
\hline $\mathrm{E}_{\text {in } \mathrm{V} \mathrm{m}^{-1}}$ & $\mathrm{~S}$ in $\mu \mathrm{W} / \mathrm{m}^{2}$ \\
\hline 3.3 & 28,902 \\
3.0 & 23,886 \\
2.7 & 19,348 \\
2.4 & 15,287 \\
2.1 & 11,704 \\
1.8 & 8,599 \\
1.7 & 7,670 \\
1.6 & 6,794 \\
1.5 & 5,971 \\
1.4 & 5,202 \\
1.3 & 4,485 \\
1.2 & 3,822 \\
1.1 & 3,211 \\
1.0 & 2,654 \\
0.9 & 2,150 \\
0.8 & 1,698 \\
0.7 & 1,300 \\
0.6 & 955 \\
0.5 & 663 \\
0.4 & 425 \\
0.3 & 239 \\
0.2 & 106 \\
0.1 & 26 \\
\hline
\end{tabular}

exposure apartment shows much less variation in amplitude, as the field is several times lower when compared to the high exposure apartment. The maximum indoor field $\left(0.52 \mathrm{~V} \mathrm{~m}^{-1}\right)$ was measured at the corner window, with direct line of sight to the neighboring house with mobile phone base station antennas. Maximum outdoor field of $0.75 \mathrm{~V} \mathrm{~m}^{-1}$ was measured at the balcony facing the same next-door building with mobile phone base station antennas. The minimum field of $0.10 \mathrm{~V} \mathrm{~m}^{-1}$ was registered on the apartment area closest to the center of the building, hence demonstrating the shielding effects of the indoor walls.

Spot measurements resulted both in time averaged and maximum RF field levels. Pearson's product-moment correlation coefficient shows high correlation between the two sets of values: $\mathrm{r}=0.95$ in the high exposure apartment, and $\mathrm{r}=0.97$ in the low exposure apartment. In average, maximum values were $58 \%$ higher than time averaged values in the high exposure apartment, and $87 \%$ higher in the low exposure apartment.

In Fig. 8 a boxplot is presented comparing the high exposure apartment to the low exposure apartment (indoor areas) based on 1-min spot measurements maximum reading.

Field increase from indoor to outdoor. Comparison was also made in both apartments between the outdoor area (staying at the balcony) and the corresponding adjacent room area, which had access to the balcony. There was about a five-fold difference in mean indoor exposure levels and about a six-fold difference in mean outdoor exposure levels between the apartments. Considering maximum readings, the outdoor exposure difference was eight-fold.

Tables II and III presents the main statistics for the low exposure and high exposure apartment, expressed in $\mathrm{V} \mathrm{m}^{-1}$ (Table II) and $\mu \mathrm{W} / \mathrm{m}^{2}$ (Table III). Tables II and III statistics are based on 1-min averaged spot measurements. The maximum indoor RF field was $0.52 \mathrm{~V} \mathrm{~m}^{-1}$ and $3.00 \mathrm{~V} \mathrm{~m}^{-1}$ respectively. Maximum reading at the balcony outside the low exposure apartment was $0.75 \mathrm{~V} \mathrm{~m}^{-1}$ compared with $6.00 \mathrm{~V} \mathrm{~m}^{-1}$ outside the high exposure apartment.

\section{Discussion}

There are a limited number of studies of RF exposure levels in Sweden. A car mounted measurement system was used to map spatially some of rural, urban and city areas published in 2014 (12). Mean power density levels showed highest exposure levels at Stockholm city $\left(6,700 \mu \mathrm{W} / \mathrm{m}^{2}\right)$, followed by city of Solna $\left(3,278 \mu \mathrm{W} / \mathrm{m}^{2}\right)$ and then urban areas as represented by Göteborg, Helsingborg, Jönköping and Ljungby $\left(1,500 \mu \mathrm{W} / \mathrm{m}^{2}\right)$ and rural areas represented by Ryssby and Ekerö $\left(230 \mu \mathrm{W} / \mathrm{m}^{2}\right)$. Their study clearly indicated that higher population density results in higher RF exposure (12). They also noted that power density can vary by $>50 \mathrm{~dB}(100,000$ times) over a driving distance of $10 \mathrm{~km}$, which supports the finding in our study-high RF exposure is not required to have a good mobile telephony service reception. Note that these measurements do not represent current RF radiation due to the rapid increase of deployment of the wireless communication (8).

A RF survey in Greece, found median urban electric field (median $1.1 \mathrm{~V} \mathrm{~m}^{-1}$ ) to be significantly higher than rural levels (median $0.3 \mathrm{~V} \mathrm{~m}^{-1}$ ). As the study utilized temporal measurements with 6-min averaging from 90 installed measurements stations, the data showed large diurnal variation for stations positioned close to mobile phone base stations, with median diurnal variation of $33.8 \%$ (13). These measurements are also old.

Baltrenas et al (4) investigated a 10-story building neighboring a mobile phone base station antenna, where the height of the building was $30 \mathrm{~m}$ distanced $35 \mathrm{~m}$ from the base station. These conditions are similar to our study. The base station antenna was approximately on the same height as floor 6 . Consequently, the highest exposed floors were 5-7, with floors where the power density at the balcony was about three times higher at 6 th floor as compared to the 3rd floor. The difference was about 15 -times when comparing the RF power density at the 1st floor to the 6th floor (4).

The present measurements with means of RF radiation up to $1.3 \mathrm{~V} / \mathrm{m}\left(4,485 \mu \mathrm{W} / \mathrm{m}^{2}\right)$ at the windows in the bedrooms in the high exposure apartment imply that this exposure may almost be compared to the exposure from a mobile phone in calling mode for many hours per day. A cohort study on Swiss adolescents showed that there was an association between whole body cumulative RF radiation dose from mobile phone talk, internet use and sent SMS and symptoms like headache and exhaustibility and also a decrease in figural memory $(14,15)$.

Many research studies have shown effects from RF radiation exposure on animals below current safety levels with opened blood brain barrier and neuronal damage $(16,17)$, oxidative stress with increased production of reactive oxygen species $(18,19)$, 


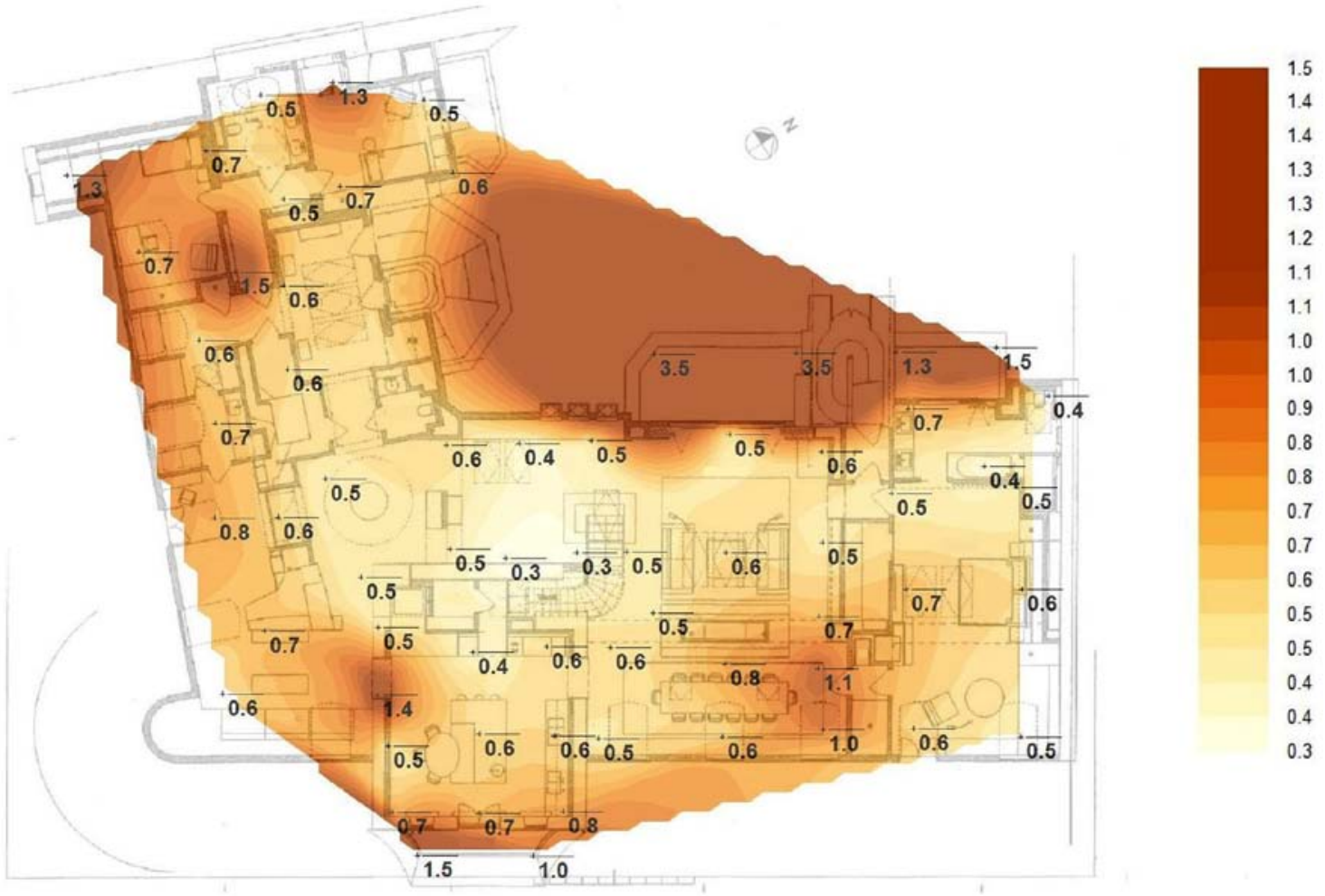

Figure 4. Spatial field distribution map of the high exposure apartment on the 6th floor; time-averaged $\mathrm{RF}$ electric field $\left(\mathrm{V} \mathrm{m}^{-1}\right)$. $\mathrm{RF}$, radiofrequency.

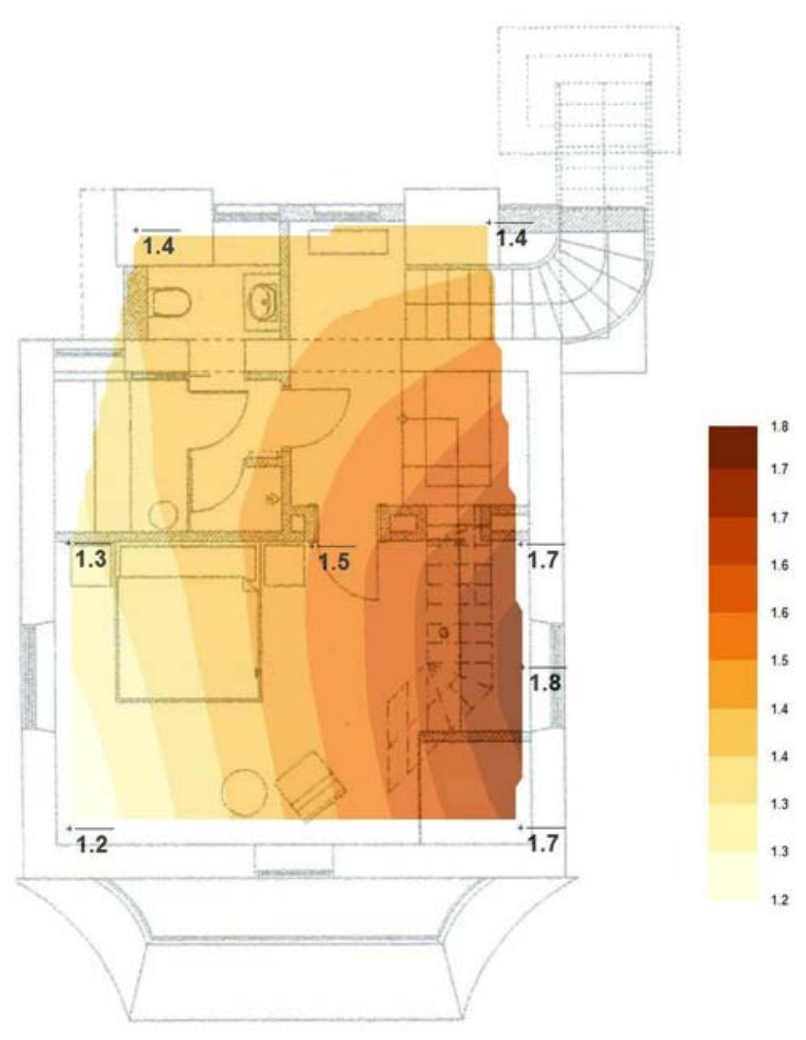

Figure 5. Spatial field distribution map of the high exposure apartment, a bedroom on the 7th floor; time-averaged $\mathrm{RF}$ electric field $\left(\mathrm{V} \mathrm{m}^{-1}\right)$. $\mathrm{RF}$, radiofrequency.

DNA-damage especially in the memory center hippocampus in the brain and increase in pro-inflammatory cytokines (20).
BT@6,16m

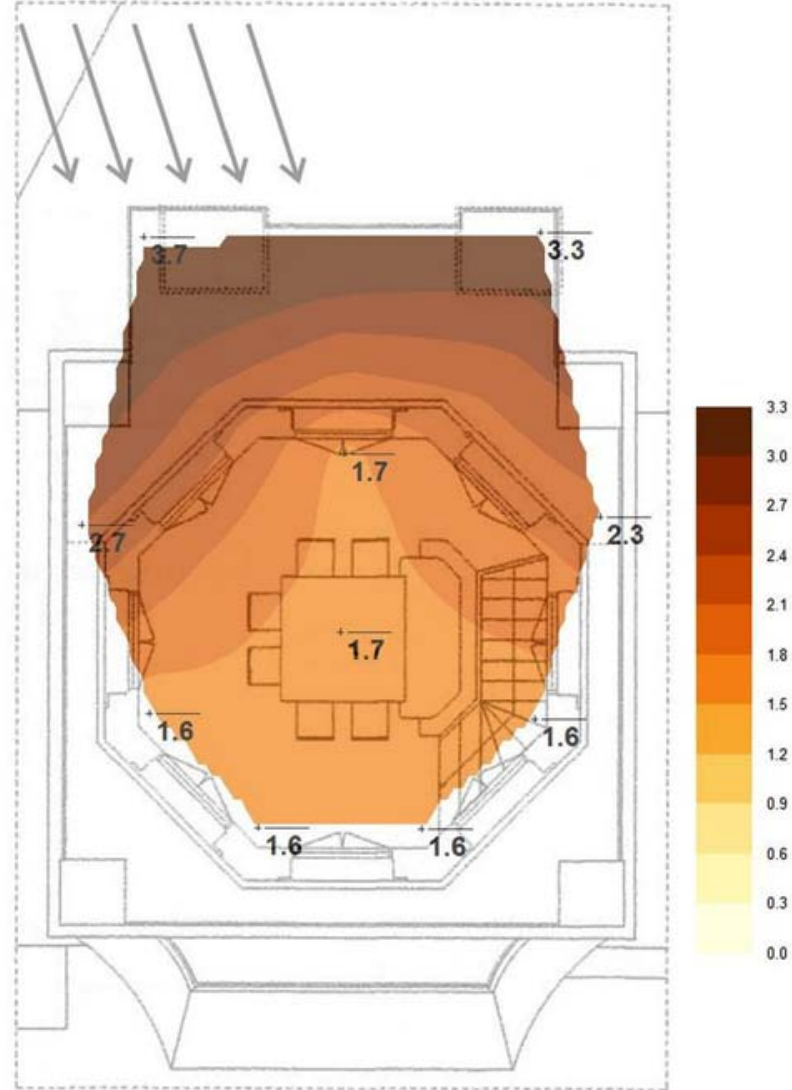

Figure 6. Spatial field distribution map of the high exposure apartment, a room on the 8th floor and on the same elevation with mobile phone base station antennas; RF radiation from base station antennas indicated with arrows; time-averaged $\mathrm{RF}$ electric field $\left(\mathrm{V} \mathrm{m}^{-1}\right)$. $\mathrm{RF}$, radiofrequency. 

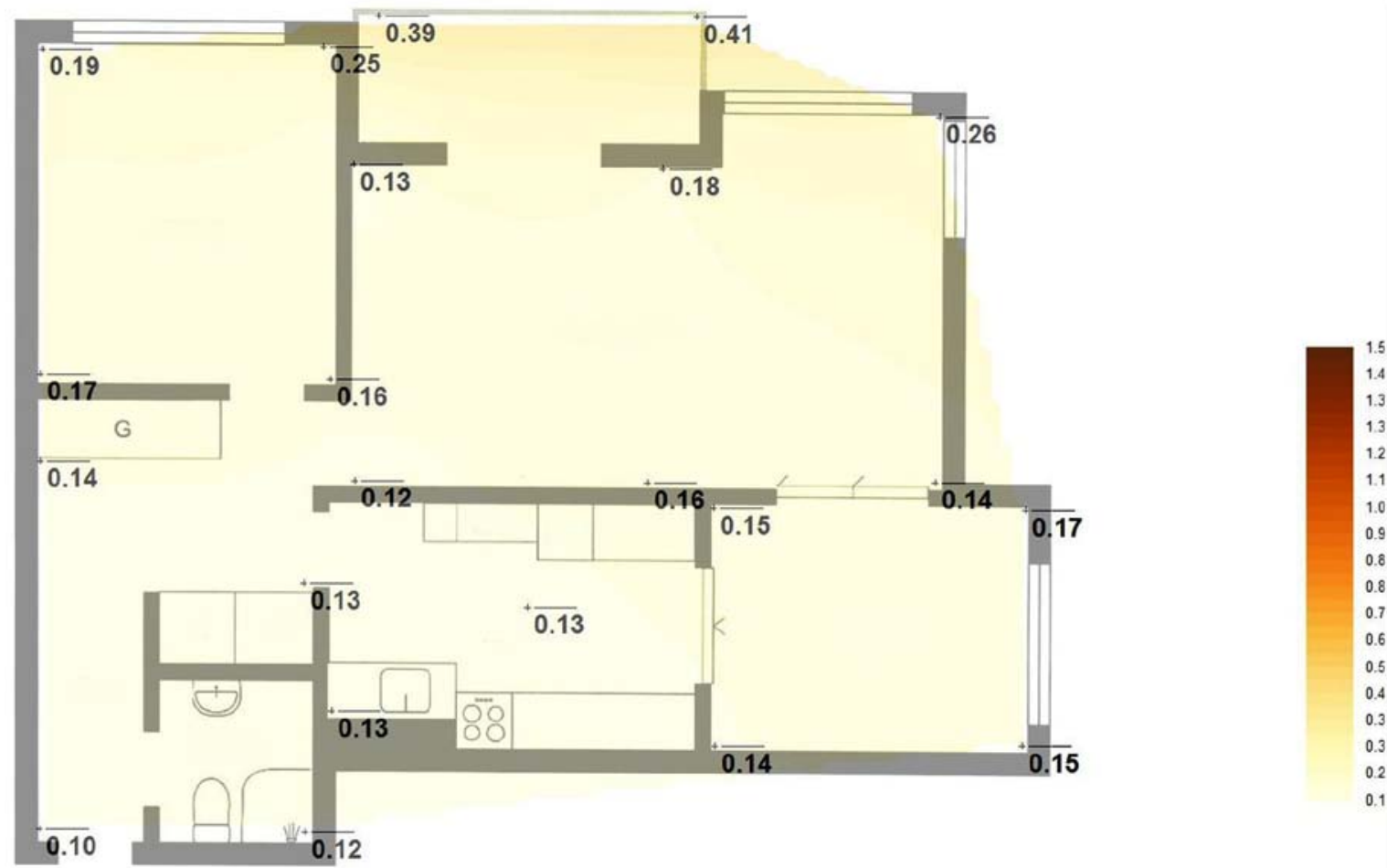

Figure 7. Spatial field distribution map of the low exposure apartment; time-averaged $\mathrm{RF}$ electric field $\left(\mathrm{V} \mathrm{m}^{-1}\right)$. $\mathrm{RF}$, radiofrequency.

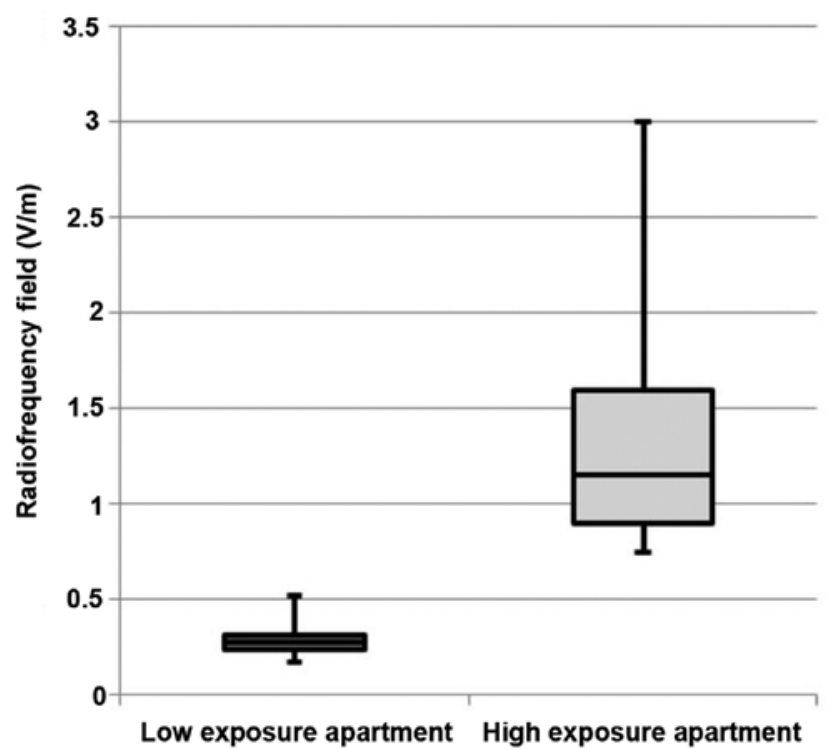

Figure 8. Box plot comparing indoor areas of the low exposure apartment to the high exposure apartment $\left(\mathrm{V} \mathrm{m}^{-1}\right)$. For median $\mathrm{RF}$ electric field the difference is more than four times; based on spot measurements maximum readings over 1-min period. Whiskers plot depicts (from bottom up) minimum, first quartile, median, third quartile and maximum of the sample containing all the spot measurement values in the area. RF, radiofrequency.

Apart from animal studies research studies on people living near mobile phone base station show augmented indications on health risks. Adverse effects have been seen on neurotransmitters in the brain (21), on hormones like cortisol, ACTH and from the thyroid, decreased levels of testosterone in men and prolactin in young women and also increase in salivary cortisol $(22,23)$. Other studies have shown lowered antioxidant levels and induced DNA damage in blood lymphocytes $(10,24)$ as well as health complaints. Symptoms like sleep disturbances, headache, fatigue, dizziness, cardiovascular symptoms depression and difficulties with memory and concentration have been reported from people living near mobile phone base stations $(25,26)$.

Human exposure has increased rapidly in recent years and will increase substantially with the introduction of the fifth generation (5G) for wireless communication (www.5gappeal.eu) $(27,28)$ and should now be regarded as an environmental pollutant. Of special concern is that $\mathrm{RF}$ radiation in the frequency range $30 \mathrm{kHz}$ to $300 \mathrm{GHz}$ was in 2011 classified as a 'possible human carcinogen' Group 2B by the International Agency for Research on Cancer (IARC) $(29,30)$. The carcinogenic evidence has by now strengthened and RF radiation should be reclassified as a known human carcinogen, Group $1(27,28)$. Environmental RF radiation is often involuntary with little possibilities to avoid, especially since mostly nothing has been done to inform and protect people from RF radiation $(31,32)$.

Especially the two bedrooms for the children in this apartment were exposed to high RF radiation, (mean 2,531 and $1,471 \mu \mathrm{W} / \mathrm{m}^{2}$ ) (9). Children will probably be exposed for a whole lifetime in contrast to the present generation. They also seem to be more sensitive for RF radiation with more immature cells in their growing bodies $(33,34)$.

A study from Taiwan calculated annual power density in watt-year $/ \mathrm{km}^{2}$ to each township from all 71,185 mobile phone base stations in service between 1998-2007. They found a statistically significantly increased risk for all neoplasms in children with higher-than-median exposure of RF radiation from base stations during five years prior to their neoplams (35). The Interphone study group calculated the estimated RF dose from mobile phones in five of the participating countries. The 
Table II. Statistics for the low and high exposure apartment. Radiofrequency field $\left(\mathrm{V} \mathrm{m}^{-1}\right)$. Mean, median and minimum values are based on the average of 1 min spot measurements (calculated based on 1 min temporal monitoring sample). The maximum is based on the same spot measurements maximum registered RF level.

\begin{tabular}{llccccc}
\hline Apartment & \multicolumn{1}{c}{ Area } & $\begin{array}{c}\text { Number of } \\
\text { measured spots }\end{array}$ & $\begin{array}{c}\text { Mean }(\overline{\mathrm{x}}) \\
\mathrm{V} \mathrm{m}^{-1}\end{array}$ & $\begin{array}{c}\text { Median } \\
\left(\mathrm{V} \mathrm{m}^{-1}\right)\end{array}$ & $\begin{array}{c}\text { Minimum } \\
\left(\mathrm{V} \mathrm{m}^{-1}\right)\end{array}$ & $\begin{array}{c}\text { Maximum } \\
\left.(\mathrm{V} \mathrm{m})^{-1}\right)\end{array}$ \\
\hline Low exposure & Indoor area & 20 & 0.16 & 0.15 & 0.10 \\
High exposure & Indoor area & 72 & 0.77 & 0.60 & 0.30 & 0.52 \\
Low exposure & Outdoor area (balcony) & 2 & 0.40 & 0.40 & 0.39 \\
High exposure & Outdoor area (balcony) & 10 & 2.46 & 2.65 & 1.00 \\
\hline
\end{tabular}

$\mathrm{RF}$, radiofrequency.

Table III. Statistics for the low and high exposure apartment. The radiofrequency field in power flow density in $\mu \mathrm{W} / \mathrm{m}^{2} . \mathrm{Mean}$, median and minimum values are based on the average of 1 min spot measurements (calculated based on 1 min temporal sample monitoring). Maximum is based on the same spot measurements maximum registered RF level.

\begin{tabular}{llcrrr}
\hline Apartment & \multicolumn{1}{c}{ Area } & $\begin{array}{c}\text { Number of } \\
\text { measured spots }\end{array}$ & $\begin{array}{c}\text { Mean }(\overline{\mathrm{x}}) \\
\text { in } \mu \mathrm{W} / \mathrm{m}^{2}\end{array}$ & $\begin{array}{c}\text { Median } \\
\left(\mu \mathrm{W} / \mathrm{m}^{2}\right)\end{array}$ & $\begin{array}{r}\text { Minimum } \\
\left(\mu \mathrm{W} / \mathrm{m}^{2}\right)\end{array}$ \\
\hline Low exposure & Indoor area & 20 & 68 & 60 & $\begin{array}{r}\text { Maximum } \\
\left(\mu \mathrm{W} / \mathrm{m}^{2}\right)\end{array}$ \\
High exposure & Indoor area & 72 & 1,573 & 955 & 26 \\
Low exposure & Outdoor area (balcony) & 2 & 424 & 424 & 404 \\
High exposure & Outdoor area (balcony) & 10 & 16,061 & 18,638 & 2,654 \\
\hline
\end{tabular}

$\mathrm{RF}$, radiofrequency.

$\mathrm{RF}$ radiation dose was estimated as total cumulative specific energy (TCSE) in $\mathrm{J} / \mathrm{kg}$ absorbed at the tumor's estimated centre. The risk for a glioma increased with increasing TSCE 7+ years before diagnoses (36). Several studies have shown increasing risks for brain tumors, especially glioblastoma multiforme, with increasing years of mobile phone use, amount of calls and calling time $(29,30,37,38)$.

In comparing two Stockholm apartments, several factors and exposure determinant could be pointed out. Both apartments were located in the vicinity of the mobile phone base station antenna, which allowed good mobile services reception indoor. Measured RF field levels in the low exposure apartment demonstrate that high exposure is not needed to provide good mobile phone reception.

Two mobile phone base stations placed very near, less than $20 \mathrm{~m}$ to an apartment may imply health risks for the inhabitants.

The low exposure apartment exposure levels were lower since the mobile phone base station was installed on top of the neighboring building, whereas on the high exposure apartment the base station was on top of the same building.

The high exposure apartment was on the top floor, with the mobile phone base station antennas situated on the roof above. The low exposure apartment was positioned seven floors lower from the roof where the base station antennas were located.

The low exposure apartment was located on the opposite side of the building from the mobile phone base station, hence

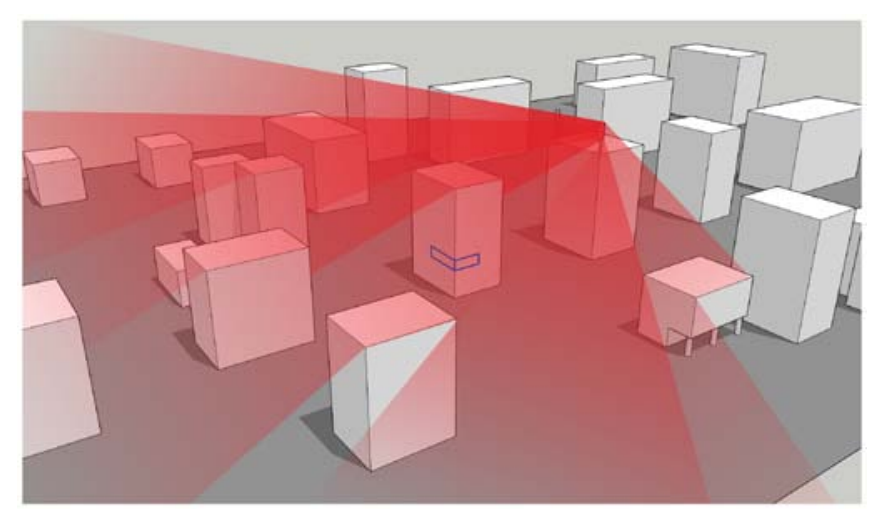

Figure 9. Mobile phone base station antenna neighboring the low exposure apartment; the buildings hinder the propagation of the RF field, especially shielding the sides facing away from the radiofrequency source; mobile phone base station antennas are sector antennas and radiate the microwaves into a direction (sector) these are aimed at. Rectangles, low exposure apartment.

the building itself provided cover (Fig. 9). Building materials, such as concrete and metal structures provide partial shielding effect against inbound radio waves.

In both apartments, indoor RF levels were several folds lower than outdoor levels of the corresponding room. Lower levels were detected also in the vicinity of the windows. This indicates a notable screening effect by the contemporary heat-reflecting windows. 
In both apartments the lowest exposure levels were registered within the center of the building, far away from the windows, shielded by the concrete or brick walls.

Although the tin roof of the high exposure apartment shields it from the majority of the inbound radio waves, countless reflections and diffraction from the structures on the roof and balconies provide the pathway to indoor. The RF field penetrated the building's constructions, including the windows and resulted in notably high exposure levels indoor.

\section{Acknowledgements}

The authors would like to thank Dr Jolanta Karpowicz, Head of Department of Bioelectromagnetics, Central Institute for Labour Protection-National Research Institute (CIOP-PIB) for the discussion regarding exposure analysis.

\section{Funding}

The present study was supported by grants from Mr. Brian Stein and Cancerhjälpen.

\section{Availability of data and materials}

The datasets generated and/or analyzed during the present study are available from the corresponding author on reasonable request.

\section{Authors' contributions}

All authors participated in the conception, design and writing of the manuscript and have read and approved the final version. TK, LH and MA conducted the measurements. MC and TK performed the statistical analysis. MC checked the statistical methods and results. LKH wrote the medical sections, contributed to the conclusions and conversion tables.

\section{Ethics approval and consent to participate}

Not applicable.

\section{Patient consent for publication}

Not applicable.

\section{Competing interests}

The authors declare that they have no competing interests.

\section{References}

1. Urbinello D, Joseph W, Verloock L, Martens L and Röösli M: Temporal trends of radio-frequency electromagnetic field (RF-EMF) exposure in everyday environments across European cities. Environ Res 134: 134-142, 2014.

2. Gajšek P, Ravazzani P, Wiart J, Grellier J, Samaras T and Thuróczy G: Electromagnetic field exposure assessment in Europe radiofrequency fields $(10 \mathrm{MHz}-6 \mathrm{GHz})$. J Expo Sci Environ Epidemiol 25: 37-44, 2015.

3. Sagar S, Struchen B, Finta V, Eeftens M and Röösli M: Use of portable exposimeters to monitor radiofrequency electromagnetic field exposure in the everyday environment. Environ Res 150: 289-298, 2016.
4. Baltrènas P, Buckus R and Vasarevičius S: Research and evaluation of the intensity parameters of electromagnetic fields produced by mobile communication antennas. J Environ Eng Lan Manage 20: 273-284, 2012.

5. Hardell L, Koppel T, Carlberg M, Ahonen M and Hedendahl L: Radiofrequency radiation at Stockholm central railway station in Sweden and some medical aspects on public exposure to RF fields. Int J Oncol 49: 1315-1324, 2016.

6. Hardell L, Carlberg M, Koppel T and Hedendahl L: High radiofrequency radiation at Stockholm old town: An exposimeter study including the royal castle, supreme court, three major squares and the Swedish Parliament. Mol Clin Oncol 6: 462-476, 2017.

7. Carlberg M, Hedendahl LK, Koppel T and Hardell L: High ambient radiofrequency radiation in Stockholm city, Sweden. Oncol Lett 17: 1777-1783, 2019.

8. Hardell L, Carlberg M, Hedendahl LK, Koppel T and Ahonen M: Environmental radiofrequency radiation at the Järntorget Square in Stockholm Old Town, Sweden in May, 2018 compared with results on brain and heart tumour risks in rats exposed to 1.8 $\mathrm{GHz}$ base station environmental emissions. World Acad Sci J 1: 47-54, 2018.

9. Hardell L, Carlberg M and Hedendahl LK: Radiofrequency radiation from nearby base stations gives high levels in an apartment in Stockholm, Sweden: A case report. Oncol Lett 15: 7871-7883, 2018.

10. Zothansiama, Zosangzuali M, Lalramdinpuii M and Jagetia GC: Impact of radiofrequency radiation on DNA damage and antioxidants in peripheral blood lymphocytes of humans residing in the vicinity of mobile phone base stations. Electromagn Biol Med 36: 295-305, 2017.

11. Aerts S, Deschrijver D, Verloock L, Dhaene T, Martens L and Joseph W: Assessment of outdoor radiofrequency electromagnetic field exposure through hotspot localization using kriging-based sequential sampling. Environ Res 126: 184-191, 2013.

12. Estenberg J and Augustsson T: Extensive frequency selective measurements of radiofrequency fields in outdoor environments performed with a novel mobile monitoring system. Bioelectromagnetics 35: 227-230, 2014.

13. Manassas A, Boursianis A, Samaras T and Sahalos JN: Continuous electromagnetic radiation monitoring in the environment: Analysis of the results in Greece. Radiat Prot Dosimetry 151: 437-442, 2012.

14. Schoeni A, Roser K and Röösli M: Memory performance, wireless communication and exposure to radiofrequency electromagnetic fields: A prospective cohort study in adolescents. Environ Int 85: 343-351, 2015.

15. Schoeni A, Roser K and Röösli M: Symptoms and the use of wireless communication devices: A prospective cohort study in Swiss adolescents. Environ Res 154: 275-283, 2017.

16. Nittby H, Brun A, Eberhardt J, Malmgren L, Persson BR and Salford LG: Increased blood-brain barrier permeability in mammalian brain 7 days after exposure to the radiation from a GSM-900 mobile phone. Pathophysiology 16: 103-112, 2009.

17. Sirav B and Seyhan N: Effects of GSM modulated radiofrequency electromagnetic radiation rbon permeability of blood-brain barrier in male \& female rats. J Chem Neuroanat 75: 123-127, 2016.

18. Yakymenko I, Tsybulin O, Sidorik E, Henshel D, Kyrylenko O and Kyrylenko S: Oxidative mechanisms of biological activity of low-intensity radiofrequency radiation. Electromagn Biol Med 35: 186-202, 2016.

19. Burlaka A, Tsybulin O, Sidorik E, Lukin S, Polishuk V, Tsehmistrenko S and Yakymenko I: Overproduction of free radical species in embryonal cells exposed to low intensity radiofrequency radiation. Exp Oncol 35: 219-225, 2013.

20. Megha K, Deshmukh PS, Banerjee BD, Tripathi AK, Ahmed R and Abegaonkar MP: Low intensity microwave radiation induced oxidative stress, inflammatory response and DNA damage in rat brain. Neurotoxicology 51: 158-165, 2015.

21. Buchner $\mathrm{K}$ and Eger $\mathrm{H}$ : Changes of clinically important neurotransmitters under the influence of modulated RF-fields-a long term study under real-life conditions. Umwelt Medizin-Gesellschaft 24: 44-57, 2011.

22. Augner C, Hacker GW, Oberfeld G, Florian M, Hitzl W, Hutter J and Pauser G: Effects of exposure to GSM mobile phone base station signals on salivary cortisol, alpha-amylase, and immunoglobulin A. Biomed Environ Sci 23: 199-207, 2010.

23. Eskander EF, Estefan SF and Abd-Rabou AA: How does long term exposure to base stations and mobile phones affect human hormone profiles? Clin Biochem 45: 157-161, 2012. 
24. Gandhi G, Kaur G and Nisar U: A cross-sectional case control study on genetic damage in individuals residing in the vicinity of a mobile phone base station. Electromagn Biol Med 34: 344-354, 2015.

25. Abdel-Rassoul G, El-Fateh OA, Salem MA, Michael A, Farahat F, El-Batanouny $M$ and Salem E: Neurobehavioral effects among inhabitants around mobile phone base stations. Neurotoxicology 28: 434-440, 2007.

26. Gómez-Perretta C, Navarro EA, Segura J and Portolés M: Subjective symptoms related to GSM radiation from mobile phone base stations: A cross-sectional study. BMJ Open 3: e003836, 2013

27. Belpomme D, Hardell L, Belyaev I, Burgio E and Carpenter DO: Thermal and non-thermal health effects of low intensity non-ionizing radiation: An international perspective. Environ Pollut 242: 643-658, 2018.

28. Carlberg M and Hardell L: Evaluation of mobile phone and cordless phone use and glioma risk using the bradford hill viewpoints from 1965 on association or causation. Biomed Res Int 2017: 9218486, 2017.

29. Baan R, Grosse Y, Lauby Secretan B, El Ghissassi F, Bouvard V, Benbrahim-Tallaa L, Guha N, Islami F, Galichet L, Straif K and WHO International Agency for Research on Cancer Monograph Working Group: Carcinogenicity of radiofrequency electromagnetic fields. Lancet Oncol 12: 624-626, 2011.

30. IARC Monographs on the Evaluation of Carcinogenic Risks to Humans, Non-Ionizing Radiation, Part 2: Radiofrequency Electromagnetic Fields, vol. 102, International Agency for Research on Cancer, Lyon, France (2013). Available at: http://monographs.iarc.fr/ENG/Monographs/vol102/mono102. pdf. Accessed on April 16, 2019.

31. Starkey SJ: Inaccurate official assessment of radiofrequency safety by the advisory group on non-ionizing radiation. Rev Environ Health 31: 493-503, 2016.

32. Hardell L: World health organization, radiofrequency radiation and health-a hard nut to crack (review). Int J Oncol 51: 405-413, 2017.
33. Markovà E, Malmgren LO and Belyaev IY: Microwaves from mobile phones inhibit 53BP1 focus formation in human stem cells stronger than in differentiated cells: Possible mechanistic link to cancer risk. Environ Health Perspect 118: 394-399, 2010.

34. Morgan LL, Kesari S and Davis DL: Why children absorb more microwave radiation than adults: The consequences. J Microsc Ultrastruct 2: 197-204, 2014.

35. Li CY, Liu CC, Chang YH, Chou LP and Ko MC: A population-based case-control study of radiofrequency exposure in relation to childhood neoplasm. Sci Total Environ 435-436: 472-478, 2012

36. Cardis E, Armstrong BK, Bowman JD, Giles GG, Hours M, Krewski D, McBride M, Parent ME, Sadetzki S, Woodward A, et al: Risk of brain tumours in relation to estimated RF dose from mobile phones: Results from five interphone countries. Occup Environ Med 68: 631-640, 2011.

37. Hardell L and Carlberg M: Mobile phone and cordless phone use and the risk for glioma-analysis of pooled case-control studies in Sweden, 1997-2003 and 2007-2009. Pathophysiology 22: 1-13, 2015.

38. Coureau G, Bouvier G, Lebailly P, Fabbro-Peray P, Gruber A, Leffondre K, Guillamo JS, Loiseau H, Mathoulin-Pélissier S, Salamon R and Baldi I: Mobile phone use and brain tumours in the CERENAT case-control study. Occup Environ Med 71: 514-522, 2014.

(i) $($ This work is licensed under a Creative Commons Attribution-NonCommercial-NoDerivatives 4.0 International (CC BY-NC-ND 4.0) License. 